\title{
Mutually pulse-coupled neurons that do not synchronize in isolation can synchronize via reciprocal coupling with another neural population
}

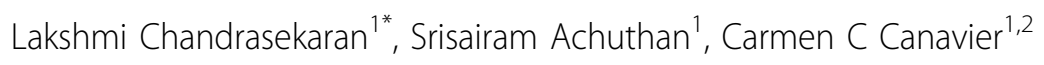

From Nineteenth Annual Computational Neuroscience Meeting: CNS*2010

San Antonio, TX, USA. 24-30 July 2010

Phase locking between similar or dissimilar clusters (synchronized groups) of neurons may be widespread in the nervous system [1-3]. We examine two reciprocally coupled clusters of pulse-coupled oscillatory neurons. Neurons within each cluster are presumed to be identical and identically coupled but not necessarily identical

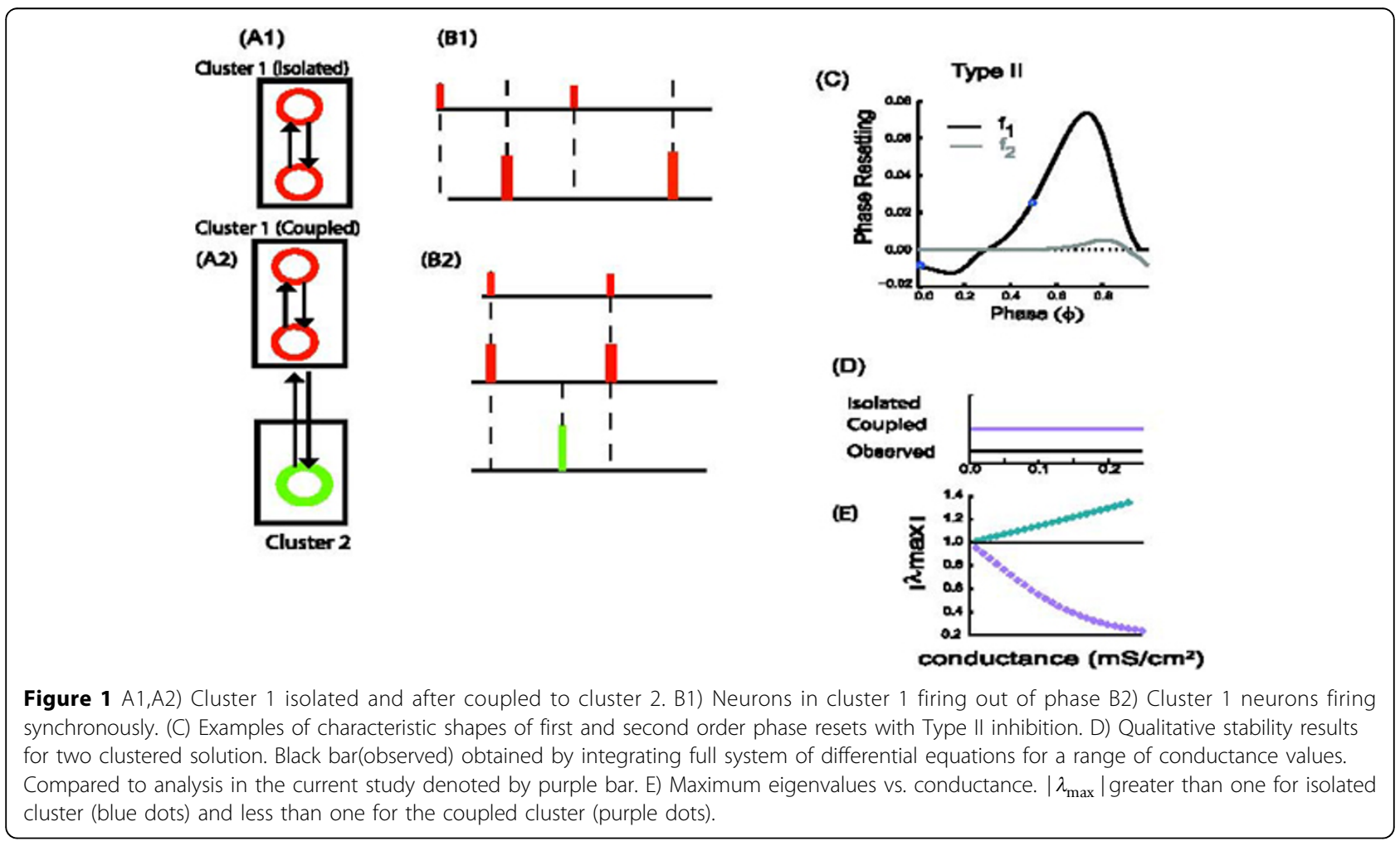

\footnotetext{
* Correspondence: Ichand@|suhsc.edu

${ }^{1}$ Neuroscience Center of Excellence, Louisiana State University Health

Sciences Center, New Orleans, LA, 70112, USA
} 
to neurons in the other cluster. We construct a discrete map using Phase Response Curves (PRCs) for a firing pattern in which the neurons within each cluster are synchronized but the two clusters fire out of phase with respect to each other. We extend this map to include a perturbation of a single neuron within one cluster and linearize about the fixed point of the original map. We derive expressions that give stability of the phase-locked cluster solution using only the slopes of the PRC at the locking points. We give an example of a cluster of inhibitory Type II excitable neurons that cannot synchronize in isolation because the absolute value of the eigenvalue that determines synchrony in the isolated cluster is greater than one. The reciprocal coupling with another cluster scales this eigenvalue such that it becomes less than one, guaranteeing stability (Figure 1). These results suggest a mechanism by which local synchronization can be induced through reciprocal coupling between brain regions via the feedback loop.

\section{Author details}

${ }^{1}$ Neuroscience Center of Excellence, Louisiana State University Health Sciences Center, New Orleans, LA, 70112, USA. ²Department of

Ophthalmology, LSU Health Sciences Center, New Orleans, LA, 70112, USA.

Published: 20 July 2010

\section{References}

1. Achuthan S, Canavier CC: Phase-locking curves determine synchronization, phase locking and clustering in networks of neural oscillators. J.Neurosci. 2009, 29(16):5218-5233.

2. Marder $E$, Calabrese R: Principles of rhythmic motor pattern generation. Physiol. Rev. 1996, 76:687-717.

3. Pervouchine DD, Netoff TI, Rotstein HG, White JA, Cunningham MO, Whittington WA, Kopell $\mathrm{NJ}$ : Low-dimensional maps encoding dynamics in entorhinal cortex and hippocampus. Neural Comput 2006, 18:2617-2650.

doi:10.1186/1471-2202-11-S1-P15

Cite this article as: Chandrasekaran et al:: Mutually pulse-coupled neurons that do not synchronize in isolation can synchronize via reciprocal coupling with another neural population. BMC Neuroscience 2010 11(Suppl 1):P15.

\section{Submit your next manuscript to BioMed Central} and take full advantage of:

- Convenient online submission

- Thorough peer review

- No space constraints or color figure charges

- Immediate publication on acceptance

- Inclusion in PubMed, CAS, Scopus and Google Scholar

- Research which is freely available for redistribution

Submit your manuscript at www.biomedcentral com/submit 